\title{
Correction of Special Vehicle Fuel Allowance in Operation Practices
}

\author{
Nikolay Lobov ${ }^{1}$, Evgeniy Genson ${ }^{1 *}$, Dmitriy Malcev ${ }^{1}$, and Dmitriy Repeckiy ${ }^{1}$ \\ ${ }^{1}$ Perm National Research Polytechnic University, 29 Komsomolskiy prosp., Perm, 614990, Russia
}

\begin{abstract}
The article is devoted to the description of the correction method of special vehicle fuel allowance, doing the collection and transporting solid municipal wastes. The developed mathematical model is presented, and allows to predict fuel consumption of the special vehicles in operation practices. Its efficacy was proved. Software implementation was offered in vehicle companies for practice using of the correction method of fuel allowance.
\end{abstract}

\section{Introduction}

With the development of free market economy in Russia and increasing of the market competition in transportation of solid household wastes (SHW), every specialized vehicle company (SVC) has to struggle for competitiveness of services they offer. There are more than 20 vehicle companies in Perm, transporting SHW. It is very important for them to improve effectiveness of their activity and optimize expenses, connected with the transportation process. Optimization and reducing of material cost on vehicle operation is the most important for increasing effectiveness of the vehicle company. One of the main budget items on SHW transportation is fuel cost, which can reach $30 \%$ in the structure of costs overall (fig.1) [1,2]. Significant attention is paid to the questions of truck's routes optimization in Russia and in other countries, especially garbage trucks and providing security while transporting dangerous wastes $[3,4,5,6,7,8,9,10]$. Thus, the problem of increasing effectiveness of using fuel by special vehicles for collecting and transporting solid household wastes is actual.

\footnotetext{
* Corresponding author: genson4@yandex.ru
} 


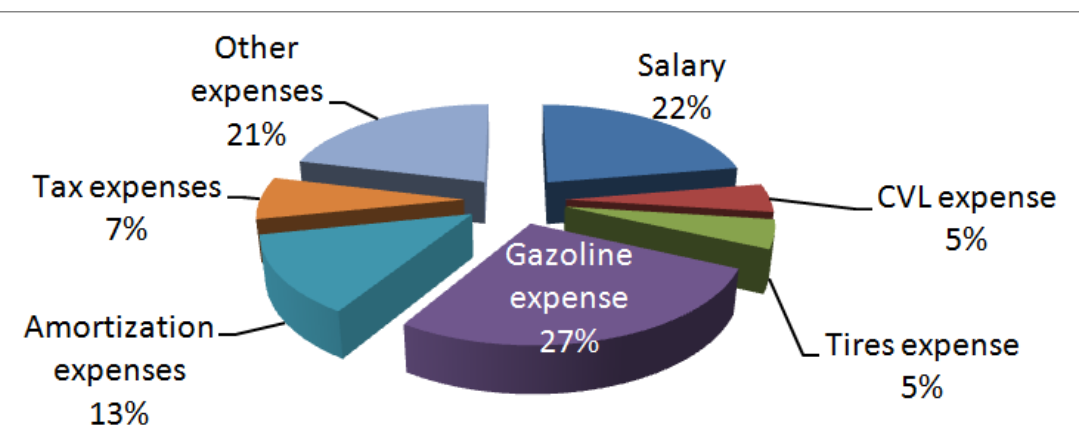

Fig. 1. Expense structure of the vehicle company

At the moment fuel allowance of the special vehicle for collecting and transporting SHW (garbage trucks) is determined according to "Guidelines for fuel allowance of the vehicles for road maintenance and repair and objects of beautification", confirmed by State Committee for Construction of Russia in 2004 [11].

Garbage truck works in two main regimes: transport regime (SHW disposal) and technological regime (collecting SHW) [12]. Working in transport regime, garbage truck moves between container yards and SHW disposal facility, and only base unit is used in working process. Loading and disposal back of a garbage truck with the help of special equipment is carrying out in technological regime $[13,14]$. The problem of reducing real fuel consumption in transport regime is widely developed nowadays [15,16]. However, previous investigations practically haven't examined technological regime of special vehicle work.

Existing uplifts to the standard fuel allowance don't reflect and take into consideration all conditions of garbage truck operation in technological working regime, in particular weight of loading wastes, that's why standards in SVC, as usual, are calculated according to top limit, and not allowed in appropriate way to determine excess fuel flow and find out the reason of this excess: bad technical condition of special equipment, bleeding in hydraulic system, bad driving, stealage and so on $[17,18]$. This means, that present methodological recommendations of determining standard fuel allowance of the garbage trucks demand additional corrections for technological regime.

\section{Material and methods}

Mathematical model of fuel allowance organization in technological regime was developed during the investigation. It consists of complex working of two subsystems:

- Subsystem "combustion engine - pump";

- Subsystem "pump-hydraulic - cylinder".

We offer to present mathematical model as a new dependence of a fuel allowance organization in technological regime of a garbage truck on the weight of loading wastes and engine speed of a base unit:

$$
Q_{\text {tech }}=\sum_{i=1}^{k} \frac{m_{i} \cdot \omega_{e}^{i} \cdot g \cdot V_{0} \cdot z_{e-p} \cdot g_{e} \cdot k_{l} \cdot t_{u p}^{i}}{\left(S_{p}-S_{s t}\right) \cdot \eta_{d} \cdot \eta_{p} \cdot \eta_{h s} \cdot \rho_{f}} \cdot K_{o p},
$$

$Q_{\text {tech }}$ - standard fuel allowance in technological regime, $1 ; k$ - quantity of loaded containers with SHW; $g$ - free falling acceleration, $\mathrm{m} / \mathrm{s}^{2} ; V_{0}-$ pump capacity per revolution, $\mathrm{m}^{3} ; \omega_{e}^{i}$ - engine speed of a base unit, $\sec ^{-1} ; S_{p}$ - piston area of a hydraulic- 
cylinder, $\mathrm{m}^{2} ; S_{s t}-$ piston area of hydraulic-cylinder rod, $\mathrm{m}^{2} ; z_{e-p}$ - transfer ratio from engine to pump, $\eta_{d}$ - drive efficiency from engine through transmission and drop box; $\eta_{h s}-$ hydraulic system efficiency; $\eta_{p}$ - pump volume efficiency; $k_{l}$ - index, taking into account geometric conditions of lifting device; $m_{i}$ - weight of loading wastes, $\mathrm{kg} ; K_{o p}-$ index, taking into additional operations while loading of a garbage truck back.

\section{Results}

To check the performance of the mathematical model live experiment was made [19]. As a subject of investigation we chose the most popular garbage truck with the rear load BM53229-1on the unit base of Kamaz-65115 (fig.3) [20]. For defining the quantity of fuel, which was used for technological operations, we have chosen weight method, based on defining weight of real fuel consumption, which was fixed for every regime of container loading on a scale. Weight was fixed with the help of developed earlier onboard weighting system, based on defining the weight according to the pressure of a power fluid in hydraulic system [21].

Data resulting from the experiment, are given in figure 2.

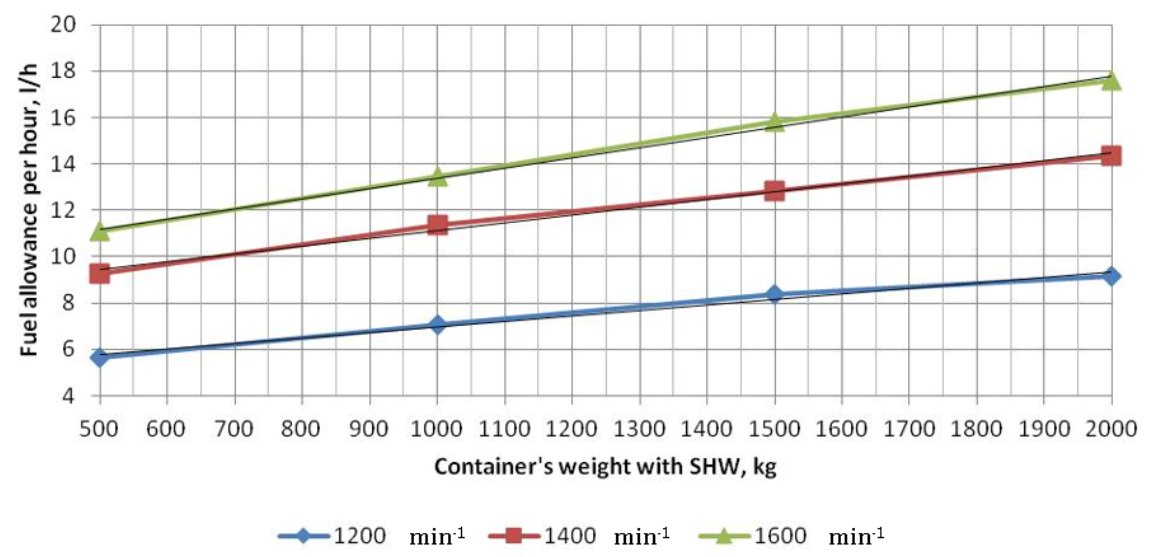

Fig. 2. Changing of the fuel flow rate on the subject of investigation.

Processing of experimental results was made and we got the equation of regression for defining fuel flow rate:

$$
G_{\text {teor }}=-17,09+0,0033 \cdot m_{0}+0,017 \cdot n,
$$

$G_{\text {teor }}$ - theoretical fuel flow rate, $1 / \mathrm{h} ; m_{0}$ - weight of the loaded container, $\mathrm{kg} ; n-$ rotation frequency of the engine base unit, $\mathrm{min}^{-1}$.

The control showed that equation is statistically significant with the probability of more than 0,95 and describe existing process adequately. We found out that the most significant factor which influence on the fuel flow rate of the garbage truck is the engine speed of a base unit.

\section{Discussion}

For practical implementation results of investigations, allowing to reduce operating costs of the vehicle company, we developed "Method of deferential correction of fuel allowance", 
taking into account different load weight, including sequence of actions SVC's employees for proper fuel traffic record in the company. As a basis of this method we took existing methodological recommendations to define standard fuel allowance. Offered method is different because it allows to define standard fuel allowance of the garbage truck in technological regime, depending on load weight of the wastes and speed engine of the base unit.

$$
Q=\left(0,01 \cdot H_{s} \cdot S+Q_{\text {tech }}\left(m_{0} ; \omega_{e}\right)\right) \cdot(1+D)+0,25 n,
$$

$Q$ - standard fuel allowance for per calendar day; $H_{s}$ - linear standard of fuel allowance, $1 / 100 \mathrm{~km} ; S$ - average daily run of the vehicle, $\mathrm{km} ; n$ - average per shift routes; $D$ - summary relative increase to linear fuel allowance; $Q_{\text {tech }}\left(m_{0} ; \omega_{e}\right)$ - fuel allowance during work of special equipment, calculated with the help of developed mathematical model , 1 (per shift).

For the purpose of strategic correction of fuel allowance in the vehicle company it is necessary to get and process data about quantity and weight load of containers with SHW. Here (fig.3) you can see a procedure of defining fuel allowance per shift on the basis of developed mathematical model.

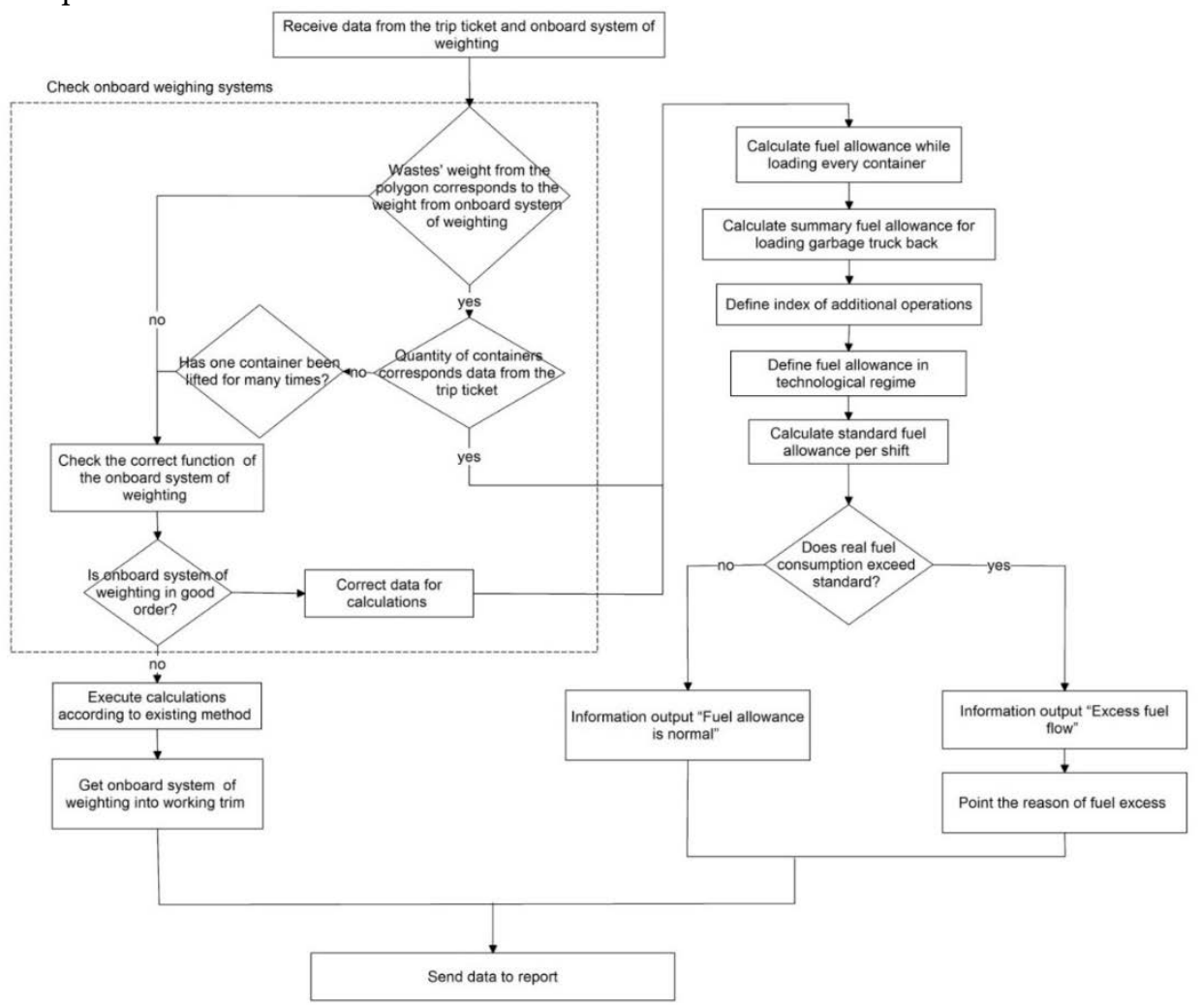

Fig. 3. Procedure of defining standard fuel allowance of the garbage truck.

With the help of developed automatic onboard system of weighting it is possible to do collecting, processing and transmitting data about date, time and place of SHW loading, quantity and weight load of containers with SHW, and also time of loading process in technological regime. We define fuel allowance while loading every container with SHW and quantity of fuel, used for loading back of the garbage truck, on the basis of received data within investigations of interactions and mathematical model. On the basis of received 
data we define standard fuel allowance of the garbage truck per shift. This value is compared with the quantity of real fuel consumption. If there is significant discrepancy in data, an employee of engineering-technical service (ETS) of SVC, tries to find out the reason.

Software implementation is offered in every vehicle company for simple using of the developed model. ETS employee loads basic data: driver-operator, make and model of the vehicle, total kilometers logged, quantity of real fuel consumption, then he chooses correction index out of offered list and does data upload to the program with on board system of weighting (quantity of loaded containers, weight of every container, time of container loading, time of working in technological regime). Program automatically calculates standard fuel allowance in technological regime and standard fuel allowance per shift, compares it with the quantity of real fuel consumption. A report about driveroperator's work, about possible defects of the elements and systems of the vehicle, leading to reducing fuel efficiency, is formed on the basis of past experience for specified period.

The analysis of technical-and-economic indexes work of the SVC allowed to draw a conclusion that practical implementation of developed model will give an opportunity to reduce specific given cost up to $4,4 \%$, based on reducing of annual operating cost, all this allow to save money on car operation up to 200 thousand rubles.

\section{Conclusion}

Analyzing factors which influence on fuel allowance of the garbage trucks in technological regime showed that load weight of the wastes and speed engine of the base unit influence greatly on the fuel allowance. We found out that the most significant factor which influenced fuel allowance per hour is the speed engine of the base unit.

Mathematical model of garbage truck fuel allowance forming in technological regime was developed. There were taken into account for the first time: weight load and speed engine of the base unit. We proved the adequateness of the developed mathematical model to the real object. Model allows predicting fuel allowance per hour in technological regime operating of garbage trucks with diesel engine.

We stated experimental regularities of fuel allowance per hour changings in technological regime of vehicle operating from weight of the loading wastes and speed engine.

On the basis of stated regularities we developed method of differential correction standard fuel allowance taking into account loading of the vehicles with different weight load. Using developed method will allow reducing specific given cost up to $4,4 \%$, and all this allow to save money on car operation up to 200 thousand robles.

\section{References}

1. A. Procenko, M. Malutin, Using technical control devices for reducing maintenance cost of lorry trucks. Technique and technology of construction, 1(1), pp.96-103 (2015)

2. S. Sandhu, C. Frey, B.-H. Shannon, E.Jones, Real-world activity, fuel use, and emissions of diesel side-loader refuse trucks. Atmospheric Environment, 129, pp. 98104 (2016)

3. N. Jovičić, Route optimization to increase energy efficiency and reduce fuel consumption of communal vehicles. Thermal Science, 14, pp. 67-78 (2011)

4. A. Tevyashev, O. Matvienko, O. Shiyan, Geoinformation analytical system of operating planning of garbage trucks' routes. East European journal of advanced technologies, 4(74), pp. 36-42 (2015) 
5. A. Tryascin, Highway transportation of dangerous wastes. The world of transport and technological machines, 1(56), pp. 107 - 113 (2017)

6. A. Novikov, A. Katunin, A. Semkin, V. Vasilieva, Intellectual managing system of cargo transportation. Actual directions of scientific researches of the XXI century: theory and practice, 5-3 (16-3), pp. 151-159 (2015)

7. W. Saibuatrong, N. Cheroennet, U. Suwanmanee, Life cycle assessment focusing on the waste management of conventional and bio-based garbage bags. Journal of Cleaner Production, 158, pp. 319-334 (2017)

8. S. Ajaykumar, P. Deepak, A. Kuldeep, Municipal solid waste management. Procedia Environmental Sciences, 35, pp. 119 - 126 (2016)

9. L. Gengyuan, H. Yan, D. Liang, Y. Zhifeng, Z. Yan, U. Sergio, An emergy-LCA analysis of municipal solid waste management. Resources, Conservation and Recycling, 120, pp. 131-143 (2017)

10. P. Cobbinah, M. Addaney, K. Agyeman, Locating the role of urbanites in solid waste management in Ghana. Environmental Development, 24, pp. 9-21 (2017)

11. Resolution of State Committee for Construction from 09.03.2004 N 36 "Guidelines for fuel allowance of the vehicles for road maintenance and repair and objects of beautification".

12. M. Altunina, Perfection of technical service system and repair of the garbage trucks: dis. ... candidate of tech. science. p. 145 (2015)

13. V. Zubov, A. Domnitskiy, R. Kargin, Calculation and choice of grip parameters for garbage truck manipulator. Procedia Engineering, 129, pp. 896 - 902 (2015)

14. R. Kargin, I. Yakovlev, E. Shemshura, Modeling of workflow in the grip-containergrip system of body garbage trucks. Procedia Engineering, 206, pp. 1535-1539 (2017)

15. G. Tavares, Z. Zsigraiova, V. Semiao, Case study of fuel savings through optimization of MSW transportation routes. Management of Environmental Quality, 19, pp. 444454 (2009)

16. D. Zaharov, P. Koslov, L. Resnik, Distinguish regulation of fuel allowance by refrigerator vehicle while working on the delivering route. Scientific and technical herald of the Volga region, 3, pp. 119-122 (2014)

17. G. Borisov, K. Leliovskii, G. Pachurin, Towards regulation of liquid fuel allowance on the motor vehicle. Automobile operating company, 2, pp. 51-55 (2015)

18. N. Kuzmin, The problem of regulating motor vehicle fuel allowance and lubricating oils. Automobile operating company, 8, pp. 20-22 (2010)

19. N. Zakharov, Modelling of motor vehicle quality changings processes. Tumen: TumGNGU, 127 p. (1999)

20. D. Malcev, N. Lobov, M. Boyarshinov, Improvement of the solid household wastes organizing process into public transport. The world of transport and technological machines, 1(52), pp. 112 - 123 (2016)

21. D. Malcev, Improvement of the solid household wastes organizing process into public transport: dis. ...cand. tech. science 2016, 142 p. 